\title{
Perioperative Outcomes of Proximal and Distal Gastric Bypass in Patients with BMI Ranged 50-60 kg/m² -A Double-Blind, Randomized Controlled Trial
}

\author{
Marius Svanevik • Hilde Risstad • Dag Hofsø • \\ Carl Fredrik Schou • Brita Solheim • Torgeir T. Søvik • \\ Jon Kristinsson • Jøran Hjelmesath • Tom Mala • \\ Rune Sandbu
}

Published online: 12 March 2015

(C) The Author(s) 2015. This article is published with open access at Springerlink.com

\begin{abstract}
Background Proximal Roux-en-Y gastric bypass may not ensure adequate weight loss in superobese patients. Bypassing a longer segment of the small bowel may increase weight loss. The objective of the study was to compare the perioperative outcomes of laparoscopic proximal and distal gastric bypass in a double-blind randomized controlled trial of superobese
\end{abstract}

The current study is part of a work-intensive collaboration between two bariatric centers in southeastern Norway. All authors fulfill all four ICMJE criteria and have been active in planning and running the study, patient follow-up and treatment, and critical revision of the manuscript.

\begin{tabular}{l} 
Registration: www.clinicaltrials.gov no: NCT00821197 \\
\hline Both Marius Svanevik and Hilde Risstad have contributed equally to this \\
work as first authors.
\end{tabular}
work as first authors.

\begin{tabular}{l}
\hline Illustrations @Kari C. Toverud \\
\hline M. Svanevik $(凹) \cdot$ D. Hofsø· B. Solheim·J. Hjelmesæth · \\
R. Sandbu \\
Morbid Obesity Center, Vestfold Hospital Trust, Halfdan \\
Wilhelmsens alle 17, 3103 Tønsberg, Norway \\
e-mail: drsvanevik@hotmail.com \\
D. Hofsø \\
e-mail: dag.hofso@siv.no \\
B. Solheim \\
e-mail: brisol@vestreviken.no \\
J. Hjelmesæth \\
e-mail: joran.hjelmeseth@siv.no \\
R. Sandbu \\
e-mail: rune.sandbu@siv.no \\
M. Svanevik·H. Risstad · J. Hjelmesæth \\
Institute ofClinical Medicine, University of Oslo, Oslo, Norway \\
H. Risstad \\
e-mail: hiriss@outlook.com
\end{tabular}

patients. The study was conducted at two public tertiary care obesity centers in Norway.

Methods Patients with body mass index (BMI) $50-60 \mathrm{~kg} / \mathrm{m}^{2}$ were randomly assigned to a proximal $(150 \mathrm{~cm}$ alimentary limb) or a distal (150 cm common channel) gastric bypass. The biliopancreatic limb was $50 \mathrm{~cm}$ in both operations. Patients and follow-up personnel were blinded to the type of

H. Risstad • C. F. Schou • J. Kristinsson • T. Mala Department of Morbid Obesity and Bariatric Surgery, Oslo University Hospital, Oslo, Norway

C. F. Schou e-mail: cfschou@online.no

J. Kristinsson e-mail: joakri@ous-hf.no

T. Mala

e-mail: tommal@ous-hf.no

T. T. Søvik $\cdot$ T. Mala

Department of Gastrointestinal Surgery, Oslo University Hospital, Oslo, Norway

T. T. Søvik e-mail: torgeir.sovik@gmail.com 
procedure. Thirty-day outcomes including complications are reported.

Results We operated on 115 patients, of whom two were excluded at surgery, leaving 56 and 57 patients in the proximal group and distal group, respectively. The median (range) operating time was 72 (36-151) and 101(59-227)min, respectively $(p<0.001)$. Two distal procedures were converted to laparotomy during the primary procedure. Median length of hospital stay was 2(1-4)days in the proximal group and 2(124)days in the distal group. The number of patients with complications and complications categorized according to the Contracted Accordion classification did not differ significantly. However, all six reoperations were performed in the distal group, of which three were completed by laparoscopy ( $p=$ 0.01 between groups). There were no deaths.

Conclusions In superobese patients with BMI between 50 and $60 \mathrm{~kg} / \mathrm{m}^{2}$, distal gastric bypass was associated with longer operating time and more severe complications resulting in reoperation than proximal gastric bypass.

Keywords Bariatric surgery · Gastric bypass · Malabsorptive gastric bypass · Distal gastric bypass · Malabsorptive procedure $\cdot$ Laparoscopic bariatric surgery $\cdot$ Randomized controlled trial

\section{Introduction}

The mechanisms of weight loss after bariatric surgery include restriction of food intake and malabsorption of nutrients. For some procedures, altered gastrointestinal endocrine physiology may mediate weight loss through modulation of appetite and energy homeostasis [1,2].

The Roux-en-Y gastric bypass provides substantial and sustained weight loss in morbidly obese patients [3, 4]. Superobese patients (body mass index, BMI $\geq 50 \mathrm{~kg} / \mathrm{m}^{2}$ ), however, may remain morbidly obese after this procedure $[5,6]$. The biliopancreatic diversion with duodenal switch induces greater weight loss than proximal gastric bypass, possibly through greater malabsorption, but is seldom performed as a primary bariatric procedure. The biliopancreatic diversion is a more challenging and technical procedure to perform and associated with a high frequency of short- and long-term adverse events including protein-calorie malnutrition $[7,8]$.

There is no general consensus as to the optimal intestinal limb lengths to be used in gastric bypass for superobese patients [9]. Lengthening the alimentary or the biliopancreatic limb or shortening the common channel may increase malabsorption and subsequent weight loss [10]. Brolin et al. introduced the distal gastric bypass with a common channel of $75 \mathrm{~cm}$, resulting in increased weight loss but also severe metabolic problems [11]. Similar problems with malnutrition and liver failure occurred when combining a longer common channel of $150 \mathrm{~cm}$ with a short alimentary limb [12]. Building upon the work of Nelson [13], we hypothesize that a common channel of $150 \mathrm{~cm}$ combined with a long alimentary limb may ensure malabsorption without severe metabolic problems.

To the best of our knowledge, no randomized controlled trial has compared weight loss outcomes or complications of proximal and distal gastric bypass in superobese patients. In this first report, we compare the perioperative outcomes of the two procedures.

\section{Methods}

Study Design and Setting

This study is part of an ongoing two-center randomized (1:1) double-blind, controlled trial comparing proximal and distal gastric bypass in superobese patients. The trial was approved by the Regional Ethics Committee and is registered in Clinicaltrials.gov, identifier NCT00821197. Signed informed consent was obtained from all patients.

The eligibility criteria for trial inclusion were BMI 50 to $60 \mathrm{~kg} / \mathrm{m}^{2}$ at the time of referral (48 to $62 \mathrm{~kg} / \mathrm{m}^{2}$ at enrollment) and age between 20 and 60 years. Exclusion criteria included previous bariatric or major abdominal surgery, urolithiasis, chronic liver disease, and conditions associated with poor compliance. All patients referred to bariatric surgery at the study centers were reviewed for inclusion in the period January 2011 to March 2013. The patients were operated on between March 2011 and April 2013.

Both participating hospitals, Oslo University Hospital and Vestfold Hospital Trust, are public tertiary care centers, each performing over 200 bariatric procedures annually. Prior to the study, the centers had performed over 1000 proximal gastric bypass procedures and a total of 40 distal gastric bypasses. All procedures were performed by senior surgeons at Vestfold Hospital Trust (RS and BS) and Oslo University Hospital (CFS, JK, and TM) in order to reduce potential learning curve effects. All senior surgeons had performed 200 or more bariatric procedures, mostly gastric bypass, prior to the start of the study.

\section{Study Treatment}

All enrolled patients followed standard preoperative logistics, including schooling on nutrition, exercise, and what to expect after surgery. All patients were prescribed a low-calorie diet $(<1000 \mathrm{kcal} /$ day $) 3$ weeks before surgery and recommended a preoperative weight loss of $5-10 \%$. 
At each study visit, all patients underwent a physical examination and data including demographics, comorbidities, and medications were registered. Fasting blood samples were obtained, and study questionnaires completed at the hospital. Weight was measured with participants wearing light clothing and no shoes.

Type 2 diabetes was defined as fasting serum glucose $\geq 7.0 \mathrm{mmol} / \mathrm{L}$, glycated hemoglobin $(\mathrm{HbAlc}) \geq 6.5 \%$, or the use of at least one glucose-lowering medication [14]. Hypertension was defined as blood pressure $\geq 140 / 90 \mathrm{mmHg}$ or the use of at least one antihypertensive medication [15].

\section{Surgical Procedures}

Both procedures were performed with an antegastric antecolic Roux-en-Y configuration using linear staplers and an omega loop [16]. Standard port placement was applied with four bladeless trocars and a Nathanson liver retractor (Cook Medical), and an extra 5-mm port was inserted if needed. All stapling was performed using a linear stapler, with blue cartridges for the stomach and white cartridges for the small bowel. The pouch was created by stapling the stomach horizontally from the minor curvature and vertically to create a gastric pouch of about $25 \mathrm{ml}$. The gastrojejunostomy was created using a 45-mm stapler with blue cartridge and completed with a running suture. The omentum was not transected routinely. The biliopancreatic limb was $50 \mathrm{~cm}$ in both procedures. Limb lengths were measured sequentially using $5-\mathrm{cm}$ markers on the graspers; the bowel was held taut but not stretched.

Following the creation of the gastrojejunostomy, the alimentary limb was measured to $150 \mathrm{~cm}$ from the gastrojejunostomy in preparation for a proximal gastric bypass, with a side-to-side jejunojejunostomy created using a 45-mm stapler cartridge and closed with a running suture. In preparation for a distal gastric bypass, the common channel was measured to $150 \mathrm{~cm}$ from the ileocecal junction and marked with a suture. The bowel was then run from the gastric pouch until reaching the marker, and a side-to-side jejunoileostomy was created using a 45-mm stapler cartridge and closed with a running suture. The Roux-en-Y configuration was completed by dividing the jejunum between the anastomoses, with the patency of the gastrojejunostomy evaluated by instilling diluted methylene blue in a nasogastric tube. The fascial defects after trocars were not closed. See Fig. 1 for illustration.

\section{Postoperative Care and Follow-Up}

Participants were advised to consume liquids only during the first postoperative week, to adhere to a semiliquid diet during the second week, and to gradually introduce normal food to their diet during the third week after surgery. Low molecular weight heparin was administered subcutaneously the first 10 days after surgery, and all patients were recommended a standard daily oral supplement of a multivitamin and mineral tablet, iron, calcium, and vitamin D. Vitamin B12 was administered through injections, and ursodeoxycholic acid prescribed for 6 months in order to prevent gallstone formation, with the exception of patients who had previously undergone cholecystectomy. The first scheduled follow-up was at 6 weeks after surgery in the outpatient clinic, where we also registered 30-day complications.

\section{Study Endpoints}

In this report, we present perioperative outcomes to evaluate short-term safety. The primary endpoint of the overall study is change in BMI 2 years after surgery. Other secondary
Fig. 1 Anatomical differences between a proximal gastric bypass and $\mathbf{b}$ distal gastric bypass
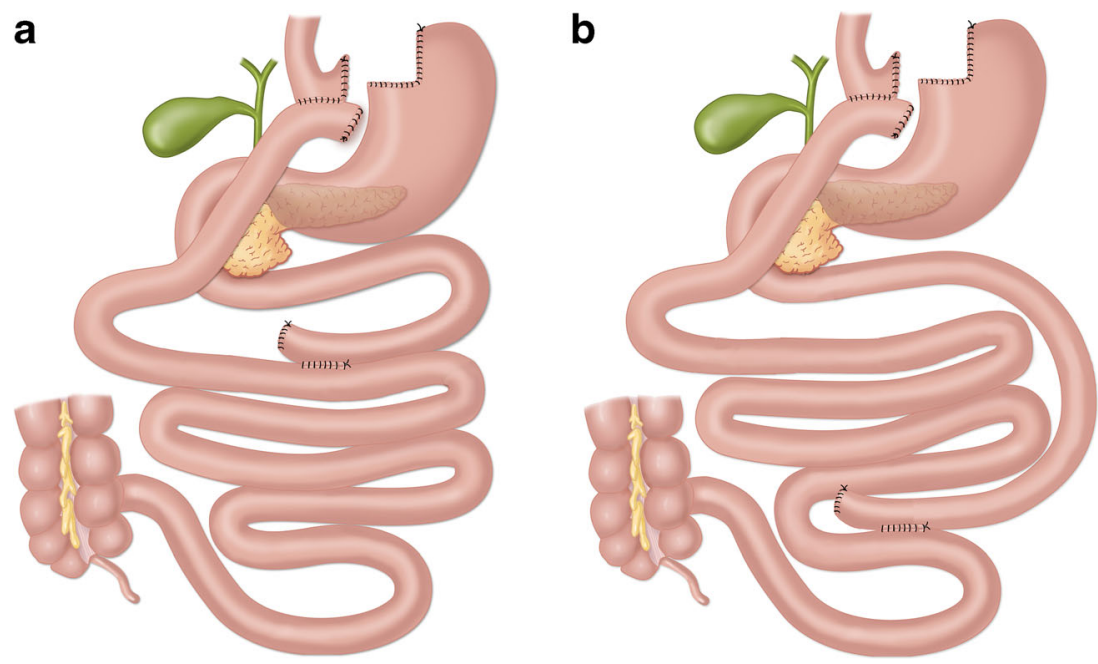
endpoints include body composition, anthropometry, obesityrelated comorbidities, health-related quality of life, gastrointestinal symptoms, and adverse events including nutritional deficiencies. All patients will be followed for 5 years.

\section{Classification of Complications}

We used the Contracted Accordion Classification to assess 30day complications. The severity of complications is categorized from 1 to 4 according to the therapy required to correct the event [17].

\section{Sample Size and Randomization}

To estimate sample size in the study, we reviewed weight outcome in morbidly obese patients who had gastric bypass surgery at the study centers. These patients had a mean BMI reduction of $15.8 \mathrm{~kg} / \mathrm{m}^{2}$ (SD 4.7) 1 year after surgery (unpublished data). We hypothesized that a distal gastric bypass would be associated with a further BMI reduction of $3.0 \mathrm{~kg} /$ $\mathrm{m}^{2} 1$ year after surgery, i.e., an estimated 1-year change in BMI of $18.8 \mathrm{~kg} / \mathrm{m}^{2}$ (SD 5.0). Assuming a similar change in BMI within the groups at 2 years and $80 \%$ power to detect a significant $(p<0.05)$ difference between the groups, we calculated that 88 patients would have to complete the study. We decided to enroll a minimum of 112 participants in order to allow for possible dropouts. The participants were block randomized (random blocks of 4 and 6) using computer-based randomization and sealed envelopes to conceal allocation.

Study participants and follow-up personnel were blinded for type of procedure. The operating surgeons were not involved in the study follow-up except in cases of surgical emergencies. Information about type of procedure was available for medical emergencies. The blinding will be lifted 5 years after surgery.

\section{Statistical Methods}

Normally distributed values are reported as mean (SD) while non-normally distributed values are reported as median (range). Chi-square and Fisher's exact test were used to compare proportions. Student's $t$ test or Mann-Whitney $U$ test were applied for the analysis of continuous data as appropriate. Ordered categorical data was compared between the treatment groups with the Mann-Whitney $U$ test. A two-sided $p$ value $<0.05$ was considered statistically significant. Statistical analyses were performed using SPSS for Windows, version 16.0, Chicago, SPSS Inc.

\section{Results}

A total of 123 patients were eligible for study inclusion and randomized to proximal or distal gastric bypass (Fig. 2). Eight patients were later either excluded or withdrew for various reasons, while two patients randomized to proximal gastric bypass were excluded during surgery when it was discovered that they had undergone major abdominal surgery. One patient underwent laparoscopic sleeve gastrectomy, the other proximal gastric bypass, with neither included in the study followup. A total of 112 patients met up at the first scheduled followup while one was contacted by phone, with all patients included in the analyses (Fig. 2).

Baseline patient characteristics are described in Table 1. All patients had an American Society of Anesthesiologists physical status classification of 3. The patients lost mean $8.4 \mathrm{~kg}$ (SD 5.1) from inclusion to the day of surgery, corresponding to a mean weight loss of $5.3 \%, p=0.12$ between groups. The median operating time was $72(36-151) \mathrm{min}$ in the proximal group and 101(59-227)min in the distal group, $p<0.001$. The median number of procedures in the study per surgeon was 22 (range 16-29), and 65\% of cases were performed by two senior bariatric surgeons. In both procedures, the median operating times varied between the surgeons. For proximal gastric bypass, the median operating times per surgeon ranged from 50 to $108 \mathrm{~min}$, and for distal gastric bypass from 84 to $123 \mathrm{~min}$. Operating times for each procedure are shown in Fig. 3. Two procedures in the distal group were converted to laparotomy; one due to intraabdominal adhesions and one due to a short bowel mesentery causing technical difficulties. The median lengths of hospital stay after proximal and distal gastric bypass were $2(1-4)$ and 2(1-24)days, respectively, $p=$ 0.29 . However, no patients in the proximal group stayed longer than 4 days, while seven patients in the distal group stayed longer than 5 days, including two who stayed for more than 20 days.

Complications categorized according to the Contracted Accordion Classification are listed in Table 2. The number of patients with complications ( 5 vs $10, p=0.18$ ) and the distribution of complications categorized according to the Contracted Accordion Classification $(p=0.11)$ did not differ significantly. All patients with severe (grade 3 ) complications, all resulting in reoperation, had received a distal gastric bypass ( 0 vs $6, p=0.01$ ). There were no deaths.

Six patients, all in the distal gastric bypass group, underwent a total of seven reoperations. Three of the reoperations were completed laparoscopically and were the result of staple line bleeding, internal herniation, and small bowel entrapment under an intraperitoneal onlay mesh. Three reoperations were performed by laparotomy. One was the result of a leakage from the enteroenterostomy and one the obstruction of the enteroenteroanastomosis, with both requiring a new anastomosis. The third patient had an iatrogenic small 
Fig. 2 CONSORT flow chart
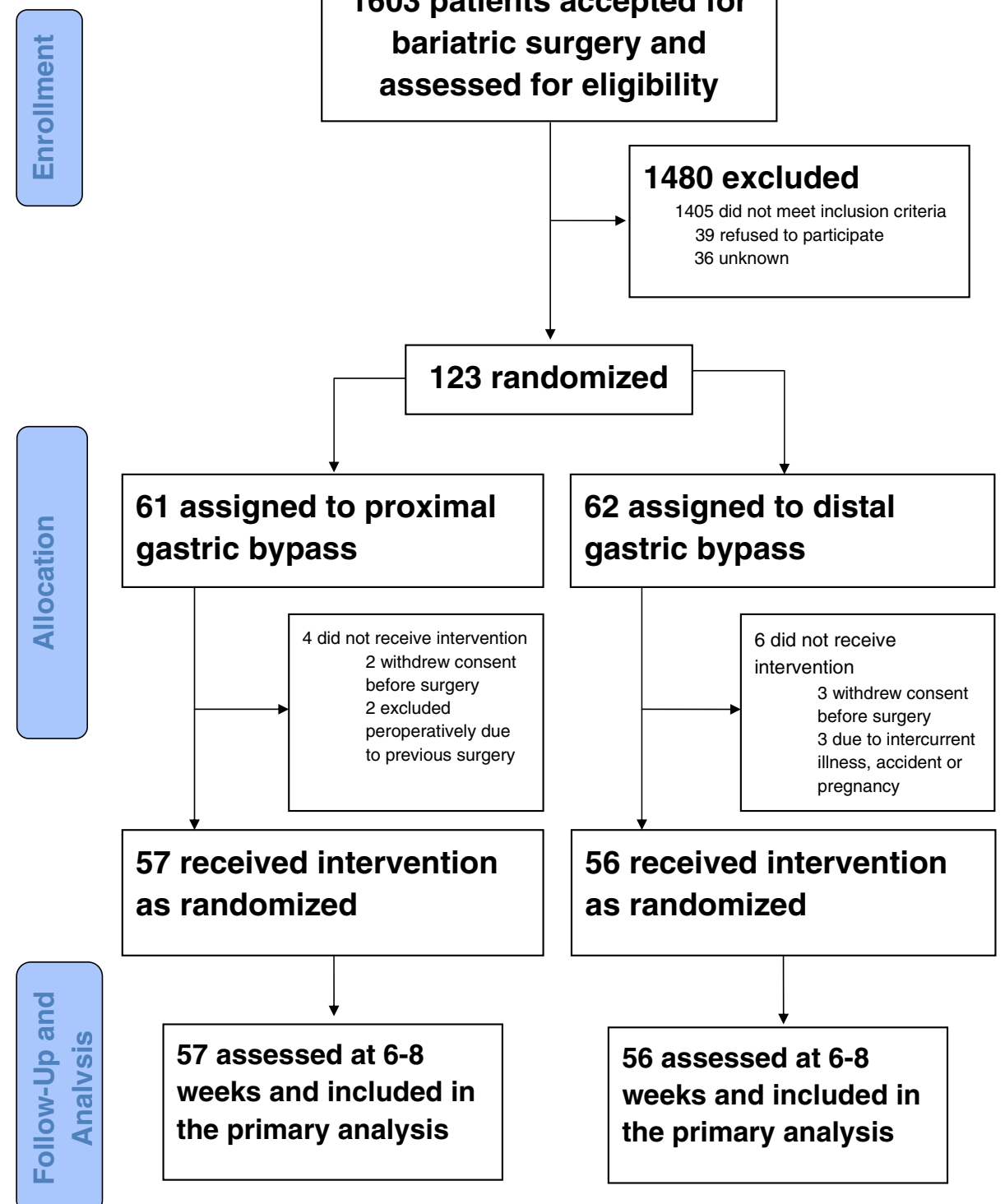

\section{3 patients accepted for bariatric surgery and assessed for eligibility}

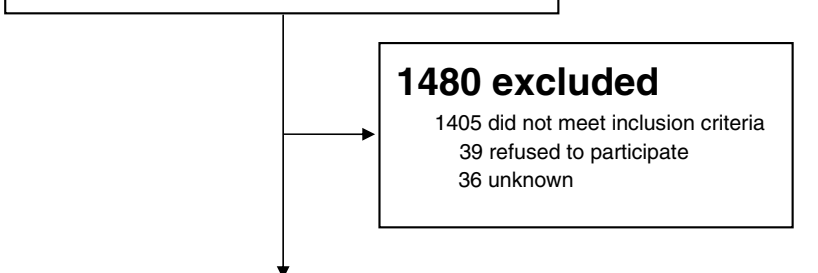

1480 excluded

did not meet inclusion 39 refused to participate

36 unknown bowel injury requiring suture, and had a second laparotomy due to bleeding after the removal of a non-suction abdominal drain.

\section{Discussion}

In the present double-blind, randomized controlled trial, we found that in patients with a BMI of 50 to $60 \mathrm{~kg} / \mathrm{m}^{2}$, distal gastric bypass was associated with longer operating time than proximal gastric bypass. The overall frequency of complications did not differ; however, distal gastric bypass resulted in more severe postoperative complications requiring reoperation than proximal gastric bypass.

The overall complication rate in the proximal group of $9.4 \%$ is comparable with that found in other studies of patients with a $\mathrm{BMI} \geq 50 \mathrm{~kg} / \mathrm{m}^{2}[6,18]$. Our finding of $18.5 \%$ overall complication rate in the distal group is higher than reported in two case series of distal gastric bypass reporting $2.8 \%$ (laparoscopic) and $13 \%$ (open) major complications. These studies, however, reported only major morbidity $[13,19]$. In contrast, one non-randomized controlled study of gastric bypass versus distal gastric bypass noted $32 \%$ complications in both groups, with a $6 \%$ overall rate of reoperation [20]. The statistical comparison of complications in the two groups should be interpreted with caution due to the low number of events.

To the best of our knowledge, five randomized controlled trials have compared intestinal limb lengths in bariatric surgery [21-25], of which four included superobese patients. Four of eight retrospective studies that evaluated the outcome of varying limb lengths included superobese patients $[5,11$, 
Table 1 Patient characteristics at baseline of 113 patients (BMI 50$60 \mathrm{~kg} / \mathrm{m}^{2}$ ) randomized to either proximal or distal gastric bypass

Proximal gastric bypass Distal gastric bypass $(n=57) \quad(n=56)$

\begin{tabular}{lll}
\hline Age, year $^{\mathrm{a}}$ & $39.4(9.3)$ & $42.0(8.2)$ \\
Women $^{\mathrm{b}}$ & $36(63 \%)$ & $37(66 \%)$ \\
${\text { Weight, } \mathrm{kg}^{\mathrm{a}}}_{\mathrm{BMI}, \mathrm{kg} / \mathrm{m}^{2 \mathrm{a}}}$ & $160(20)$ & $157(17)$ \\
Systolic BP, mmHg & \\
Diastolic BP, mmHg $^{\mathrm{a}}$ & $131(16)$ & $53.6(3.3)$ \\
Diabetes mellitus type $^{\mathrm{b}}$ & $14(25 \%)$ & $138(17)$ \\
Hypertension $^{\mathrm{b}}$ & $33(58 \%)$ & $80(12)$ \\
OSA $^{\mathrm{b}}$ & $21(36 \%)$ & $19(34 \%)$ \\
CPAP-dependent OSA $^{\mathrm{b}}$ & $17(30 \%)$ & $34(61 \%)$ \\
Joint pain $^{\mathrm{b}}$ & $33(58 \%)$ & $19(34 \%)$ \\
Depression $^{\mathrm{b}}$ & $13(23 \%)$ & $14(25 \%)$ \\
Urinary incontinence $^{\mathrm{b}}$ & $10(18 \%)$ & $90(71 \%)$ \\
Gastroesopheagal reflux $^{\mathrm{b}}$ & $14(25 \%)$ & $13(23 \%)$ \\
Hypothyroidism $^{\mathrm{b}}$ & $3(5 \%)$ & $16(29 \%)$ \\
Current smoker $^{\mathrm{b}}$ & $8(14 \%)$ & $11(20 \%)$ \\
\hline
\end{tabular}

${ }^{\mathrm{a}}$ Mean (SD)

${ }^{\mathrm{b}}$ Number of patients (percentage)

$B M I$ body mass index, CPAP continuous positive airway pressure, $O S A$ obstructive sleep apnea, $B P$ blood pressure

26, 27]. Few of the studies reported on perioperative outcome, and none have used standardized classification of complications, making direct comparison of outcomes difficult. Our finding of longer operating times when performing distal gastric bypass has been described by others and may reflect technical surgical aspects [20]. The main difference between the proximal and distal bypass is the handling of the small bowel.
Table 2 Perioperative complications in superobese patients randomized to either proximal or distal gastric bypass stratified according to the Contracted Accordion Classification

\begin{tabular}{|c|c|c|}
\hline Complications & $\begin{array}{l}\text { Proximal gastric } \\
\text { bypass }(n=57)\end{array}$ & $\begin{array}{l}\text { Distal gastric } \\
\text { bypass }(n=56)\end{array}$ \\
\hline Patients with no complication & $52(91 \%)$ & $46(82 \%)$ \\
\hline 1. Mild complications & 4 & 2 \\
\hline Pneumomediastinum & 1 & 0 \\
\hline Hematoma & 1 & 1 \\
\hline Hematochezia & 0 & 1 \\
\hline $\begin{array}{l}\text { Superficial skin burn from } \\
\text { warm liver retractor }\end{array}$ & 1 & 0 \\
\hline Hypertension & 1 & 0 \\
\hline 2. Moderate complications & 1 & 2 \\
\hline Urinary tract infection & 1 & 0 \\
\hline Intraabdominal abscess & 0 & 1 \\
\hline Melena & 0 & 1 \\
\hline 3. Severe complications & 0 & 6 \\
\hline Small bowel obstruction & 0 & 2 \\
\hline Intraabdominal bleeding & 0 & 1 \\
\hline $\begin{array}{l}\text { Leakage at the } \\
\text { enteroenteroanastomosis }\end{array}$ & 0 & 1 \\
\hline Small bowel perforation & 0 & $1^{\mathrm{a}}$ \\
\hline Ventral hernia recurrence & 0 & 1 \\
\hline 4. Deaths & 0 & 0 \\
\hline
\end{tabular}

${ }^{\mathrm{a}}$ The patient underwent a second laparotomy due to bleeding after removal of an abdominal drain

There is more manipulation, and the long alimentary limb increases the strain on the enteroenteroanastomosis. Most reoperations observed in our study were related to the small bowel. Changes in surgical technique and greater experience with the handling of the distal small bowel while creating the
Fig. 3 Operating times for proximal (triangle) and distal gastric bypass (squares) over the course of the study. Days from study start are indicated on the $x$ axis, and operating times in minutes on the $y$-axis. The corresponding fitted curves are estimated by LOWESSregression curves (locally weighted scatterplot smoothing)

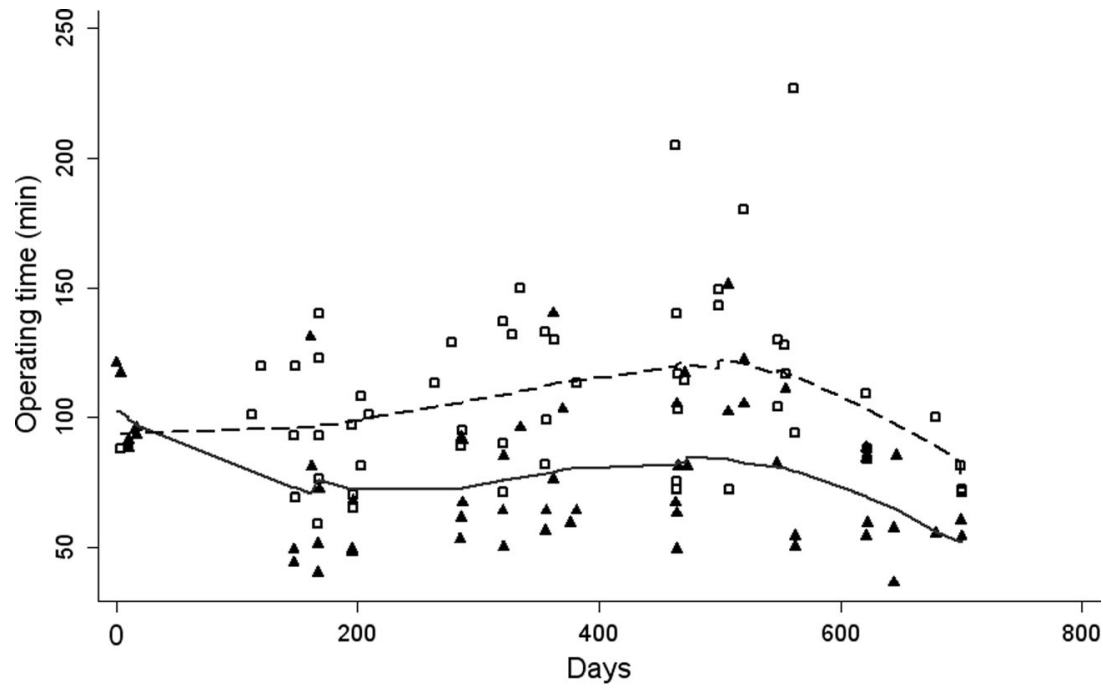

Proximal gastric bypass Distal gastric bypass 
enteroenteroanastomosis might reduce the differences in operating time and complication rates. Dividing the short bowel before fashioning the gastrojejunal or the jejunojejunal anastomosis might lead to less small bowel-related complications than using the omega loop technique. Of the other studies, only Nergaard et al. describes using the omega loop technique [25], but in most studies this is not specified. Some advocate dividing the mesenterium beyond the first vascular arcade to reduce the strain on the anastomosis, but we have not used this method routinely, and increased strain on the jejunoileal anastomosis was not perceived to be a problem during the procedures.

The incidence of short-term complications for biliopancreatic diversion with duodenal switch, an alternative malabsorptive procedure, is also high. Two previous studies of duodenal switch in superobese patients, of which one was from our study group, both present complications in $24 \%$ of the patients within 30 days of surgery, one reporting $12 \%$ severe complications $[28,29]$. In a recent single-center review, laparoscopic duodenal switch had a significantly higher leak rate of $5 \%$ compared to proximal gastric bypass [8]. The distal gastric bypass may be an alternative to duodenal switch in superobese patients, although there is little evidence as to long-term outcome. Malabsorptive bariatric procedures, however, can impose adverse events that may offset the benefits of increased weight loss in the long term [30].

The major strengths of the present study include the double-blind, randomized controlled design, a high follow-up rate, and standardization of the surgical procedures. In addition, we used a well-established grading system for reporting complications, which is essential for facilitation of comparison with other studies. The study was not powered for analyzing differences in complications, thus limiting reasonable statistical comparisons of outcome between the two groups. We restricted the study to patients with a BMI of 50 to $60 \mathrm{~kg} /$ $\mathrm{m}^{2}$, and therefore the results may not apply to patients with a BMI outside of this range. The surgeons had greater experience performing proximal gastric bypass as opposed to distal gastric bypass, and learning curve effects may thus contribute to the differences observed in postoperative outcome. We tried to minimize this potential bias by limiting the number of surgeons involved; however, the small number of procedures suggest that the surgeons were still in the learning curve for the technical steps that differ between proximal and distal gastric bypass. However, the procedures are identical in all other parts than the handling of the small bowel.

The technical skills of the individual surgeon are likely to be of importance for the risk of complications. Birkmeyer et al. have shown that technical skills correlate with less complications and shorter operating time [31]. The small number of patients in our study does not allow for reasonable statistical evaluation of any potential correlation between operating times and complications; however, the mean operating times are shorter than in comparable studies [19, 20]. Cook et al. found that by standardizing the anesthetic agents and the operative steps, length of hospital stay and outcomes in regard to cardiac surgical practice improved [32]. To facilitate the use of standardized surgical technique in the present study, the surgeons at the two study centers operated a few patients together before the outset of the study. Detailed description of operative techniques might allow for more standardized care for bariatric patients and may enable comparison between studies.

Measuring the small bowel by using graspers or umbilical tape introduces risks of measurement biases. We are not aware of any studies validating these methods. Measurement of the total bowel length could have given more information on procedural effect on postoperative nutritional status and weight loss.

\section{Conclusion}

Distal gastric bypass was associated with longer operating time and a higher frequency of reoperations and severe perioperative complications than proximal gastric bypass surgery in patients with BMI $50-60 \mathrm{~kg} / \mathrm{m}^{2}$.

Acknowledgment We thank Linda Mathisen and Marianne Sæter for their assistance with patient logistics, Morten Fagerland for statistical help, and Matthew McGee for proofreading the manuscript. Finally, we thank all patients for participating in the study.

Conflict of Interest The authors declare no conflict of interest.

Informed Consent Informed consent was obtained from all individual participants included in the study.

Statement of Human and Animal Rights All procedures performed were in accordance with the ethical standards of the national research committee and with the 1964 Helsinki declaration and its later amendments or comparable ethical standards.

Funding Both of the main authors have received research grants from the South-Eastern Norway Regional Health Authority.

Open Access This article is distributed under the terms of the Creative Commons Attribution License which permits any use, distribution, and reproduction in any medium, provided the original author(s) and the source are credited.

\section{References}

1. Thivel D, Brakonieki K, Duche P, et al. Surgical weight loss: impact on energy expenditure. Obes Surg. 2012;23:255-66.

2. Borg CM, le Roux CW, Ghatei MA, et al. Progressive rise in gut hormone levels after Roux-en-Y gastric bypass suggests gut adaptation and explains altered satiety. Br J Surg. 2006;93:210-5.

3. Buchwald H, Oien DM. Metabolic/bariatric surgery worldwide 2011. Obes Surg. 2013;23:427-36. 
4. Hofsø D, Nordstrand N, Johnson LK, et al. Obesity-related cardiovascular risk factors after weight loss: a clinical trial comparing gastric bypass surgery and intensive lifestyle intervention. Eur J Endocrinol. 2010;163:735-45.

5. Christou NV, Look D, MacLean LD. Weight gain after short- and long-limb gastric bypass in patients followed for longer than 10 years. Ann Surg. 2006;244:734-40.

6. Suter M. Results of Roux-en-Y gastric bypass in morbidly obese vs superobese patients. Arch Surg. 2009;144:1-7.

7. Risstad H, Søvik TT, Engström M, et al. Five-year outcomes after laparoscopic gastric bypass and laparoscopic duodenal switch in patients with body mass index of 50 to 60: a randomized clinical trial. JAMA Surg. 2015. doi:10.1001/jamasurg.2014.3579.

8. Hedberg J, Sundström J, Sundbom M. Duodenal switch versus Roux-en-Y gastric bypass for morbid obesity: systematic review and meta-analysis of weight results, diabetes resolution and early complications in single-centre comparisons. Obes Rev. 2014;15: 555-63.

9. Madan AK, Harper JL, Tichansky DS. Techniques of laparoscopic gastric bypass: on-line survey of American Society for Bariatric Surgery practicing surgeons. Surg Obes Relat Dis. 2008;4:166-72.

10. Stefandis D, Kuwada TS, Gersin KS. The importance of the length of the limbs for gastric bypass patients - an evidence-based review. Obes Surg. 2011;21:119-24.

11. Brolin RE, LaMarca LB, Kenler HA, et al. Malabsorptive gastric bypass in patients with superobesity. J Gastrointest Surg. 2002;6: 195-203. discussion 204-5.

12. Sugerman HF, Kellum JM, DeMaria EJ. Conversion of proximal to distal gastric bypass for failed gastric bypass for superobesity. J Gastrointest Surg. 1997;1:517-24. discussion 524-6.

13. Nelson WK, Fatima J, Houghton SG, et al. The malabsorptive very, very long limb Roux-en-Y gastric bypass for super obesity: results in 257 patients. Surgery. 2006;140:517-23.

14. American Diabetes Association. Diagnosis and classification of diabetes mellitus. Diabetes Care. 2014;37 Suppl 1:S81-90.

15. James PA, Oparil S, Carter BL, et al. 2014 evidence-based guideline for the management of high blood pressure in adults. JAMA. 2014;311:507.

16. Lönroth H, Dalenbäck J, Haglind E, et al. Laparoscopic gastric bypass. Another option in bariatric surgery. Surg Endosc. 1996;10:6368.

17. Strasberg SM, Linehan DC, Hawkins WG. The accordion severity grading system of surgical complications. Ann Surg. 2009;250:17786.
18. Parikh MS, Shen R, Weiner M, et al. Laparoscopic bariatric surgery in super-obese patients (BMI>50) is safe and effective: a review of 332 patients. Obes Surg. 2005;15:858-63.

19. Thurnheer M, Bisang P, Ernst B, et al. A novel distal very long Rouxen Y gastric bypass (DVLRYGB) as a primary bariatric procedurecomplication rates, weight loss, and nutritional/metabolic changes in the first 355 patients. Obes Surg. 2012;22:1427-36.

20. Müller MK, Räder S, Wildi S, et al. Long-term follow-up of proximal versus distal laparoscopic gastric bypass for morbid obesity. $\mathrm{Br} \mathrm{J}$ Surg. 2008;95:1375-9.

21. Brolin RE, Kenler HA, Gorman JH, et al. Long-limb gastric bypass in the superobese. A prospective randomized study. Ann Surg. 1992;215:387-95.

22. Choban PS, Flancbaum L. The effect of Roux limb lengths on outcome after Roux-en-Y gastric bypass: a prospective, randomized clinical trial. Obes Surg. 2002;12:540-5.

23. Inabnet WB, Quinn T, Gagner M, et al. Laparoscopic Roux-en-Y gastric bypass in patients with BMI. Obes Surg. 2005;15:51-7.

24. Pinheiro JS, Schiavon CA, Pereira PB, et al. Long-long limb Rouxen-Y gastric bypass is more efficacious in treatment of type 2 diabetes and lipid disorders in super-obese patients. Surg Obes Relat Dis. 2008;4:521-5.

25. Nergaard BJ, Leifsson BG, Hedenbro J, et al. Gastric bypass with long alimentary limb or long pancreato-biliary limb-long-term results on weight loss, resolution of co-morbidities and metabolic parameters. Obes Surg. 2014.

26. Freeman JB, Kotlarewsky M, Phoenix C. Weight loss after extended gastric bypass. Obes Surg. 1997;7:337-44.

27. Ciovica R, Takata M, Vittinghoff E, et al. The impact of roux limb length on weight loss after gastric bypass. Obes Surg. 2007;18:5-10.

28. Buchwald H, Kellogg TA, Leslie DB, et al. Duodenal switch operative mortality and morbidity are not impacted by body mass index. Ann Surg. 2008;248:541-8.

29. Søvik TT, Taha O, Aasheim ET, et al. Randomized clinical trial of laparoscopic gastric bypass versus laparoscopic duodenal switch for superobesity. Br J Surg. 2009;97:160-6.

30. Kellum JM, Chikunguwo SM, Maher JW, et al. Long-term results of malabsorptive distal Roux-en-Y gastric bypass in superobese patients. Surg Obes Relat Dis. 2011;7:189-93.

31. Birkmeyer JD, Finks JF, O'Reilly A, et al. Surgical skill and complication rates after bariatric surgery. N Engl J Med. 2013;369:1434-42.

32. Cook D, Thompson JE, Habermann EB, et al. From "Solution Shop" model to "Focused Factory" in hospital surgery: increasing care value and predictability. Health Aff. 2014;33:746-55. 